\title{
恩地 豊(束京柇研)
}

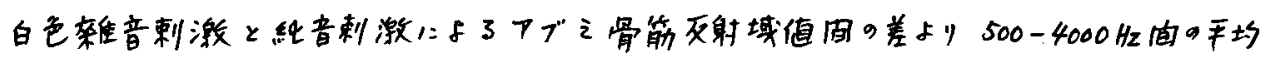

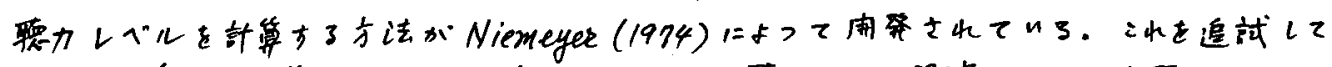

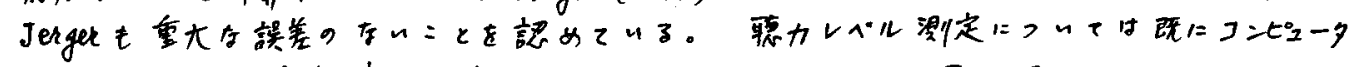

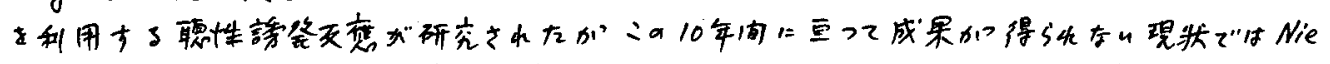

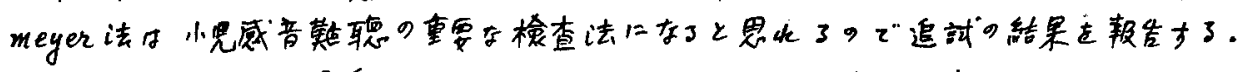

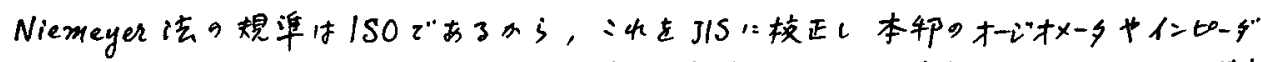
ンスメータで行えるようにした。二兆によつて本法の竍算す法とるの皘度が理解され更に精度 さ上げるたのに变法を斌みた。棈度とは成人のオージオダラムのHLと本法によ了HLの差でるる。

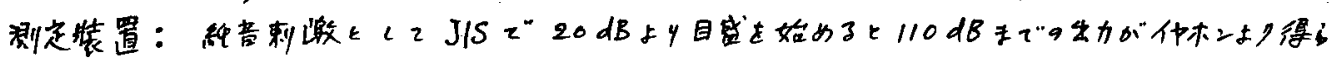

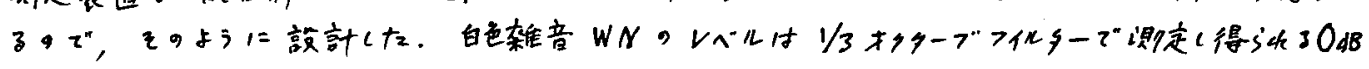

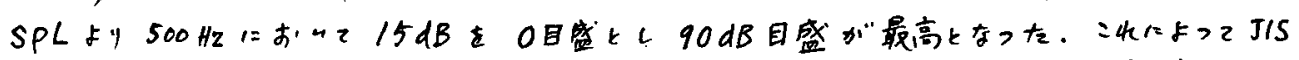

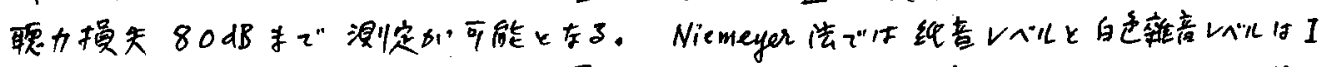

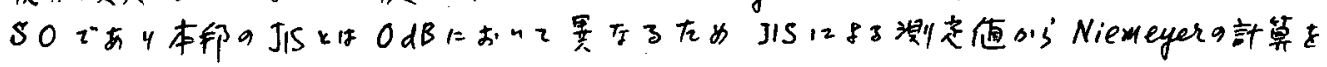
行つてもるの結果は異をるものとなる。J/S纸音レベルさ便用する孜らばWNレベルを校正

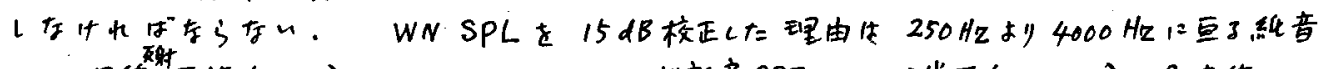

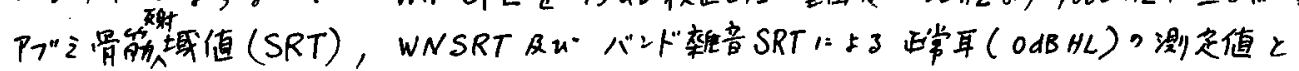

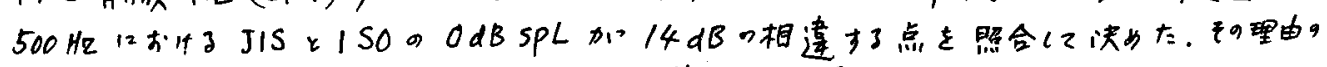

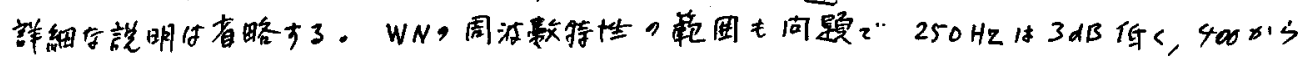

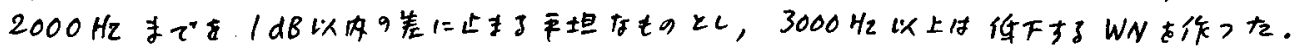

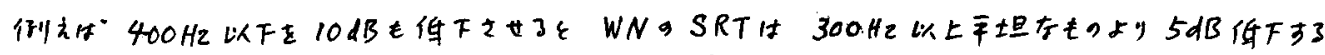

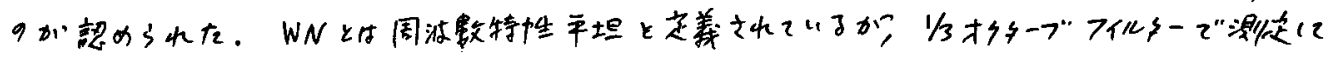

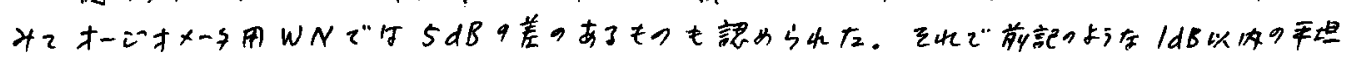

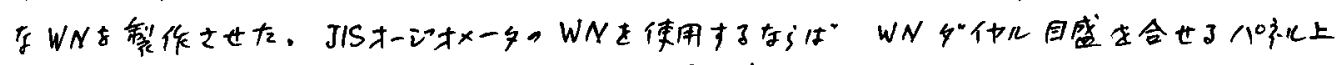

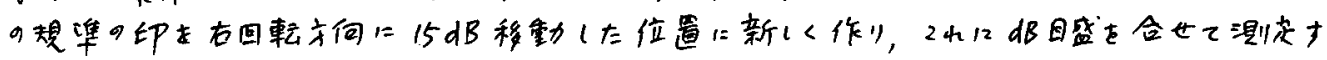

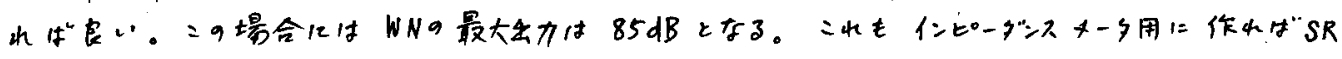

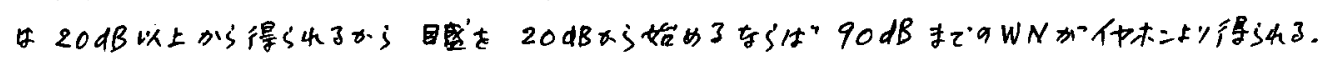

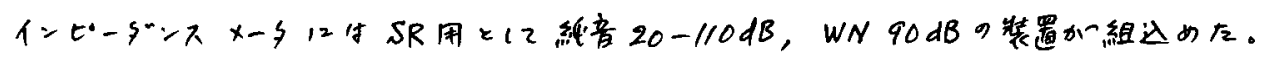

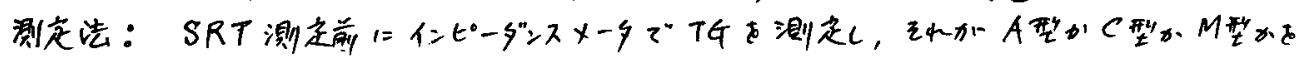

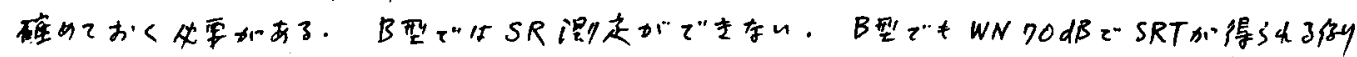

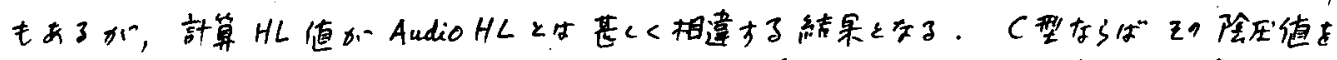

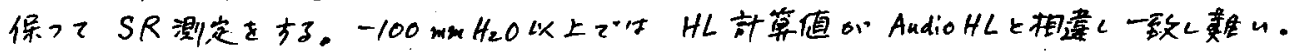

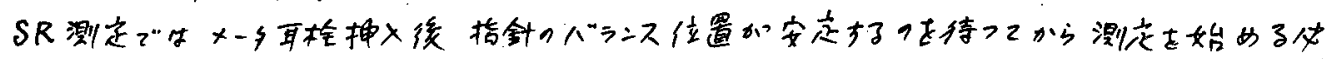

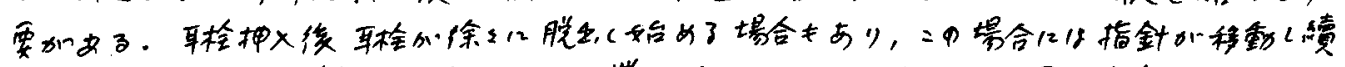

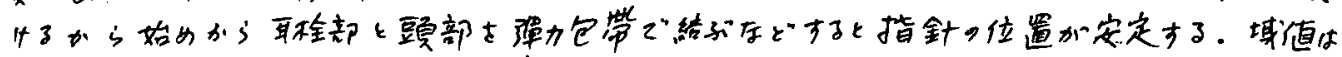

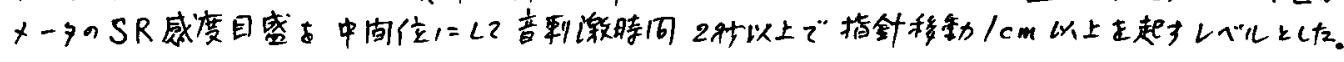


表法によ了計算法。

(1) $500,1000,2000 \mathrm{~Hz}$ 。 SRT 9平均值 (MSRT) 算出する。(z)纸音雜音域值差D

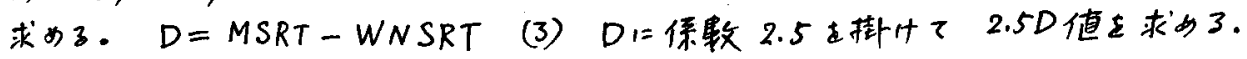

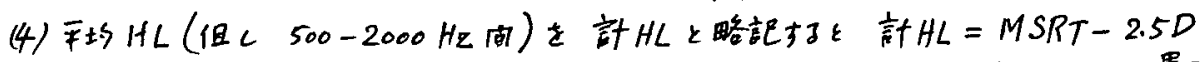

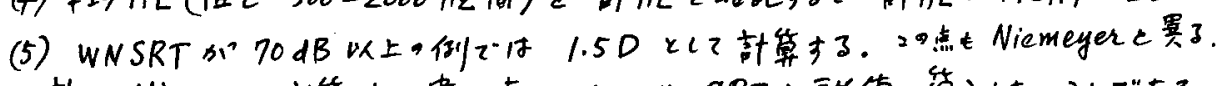

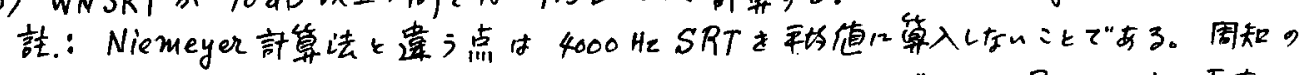

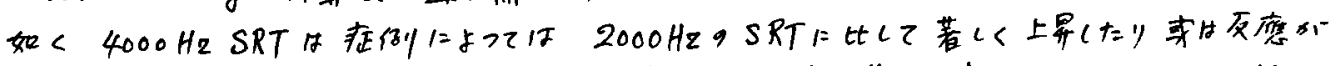

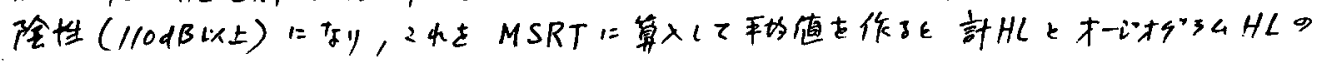

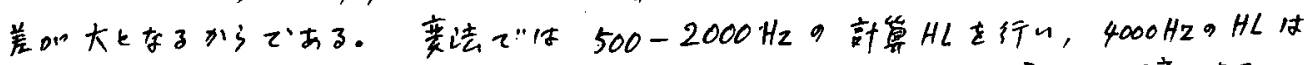

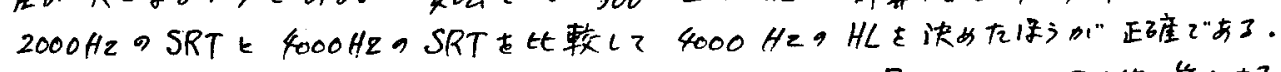

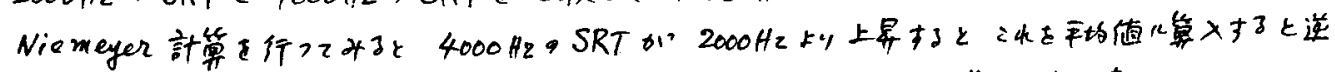

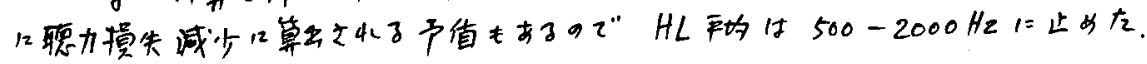

計算宽例

(1) 成人女性: Audio HL 平坞 $2.5 \mathrm{~dB}$ ，TG A型 $0.3 \mathrm{CC} ，$ MSRT $=(65+70+70) \div 3=68.7 \mathrm{~dB}$ $W N S R T=40 \mathrm{~dB}, \quad D=68.7-40=28.7 \mathrm{~dB}, 2.5 D=71.7 \mathrm{~dB}$, 計 HL=68.7-71.7=-3

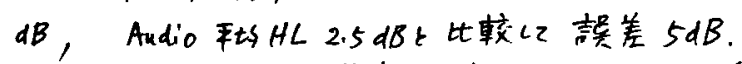

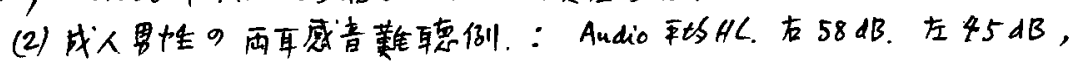

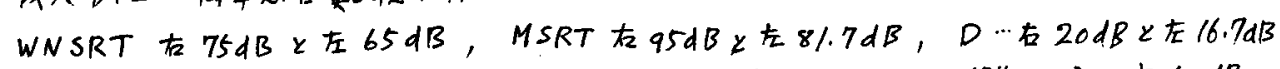

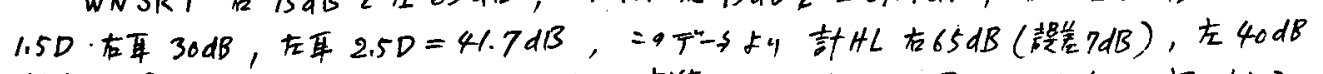

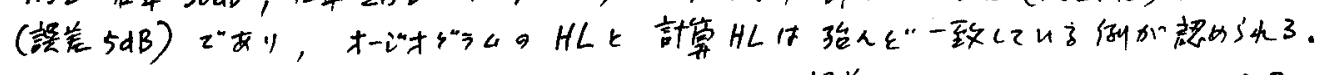

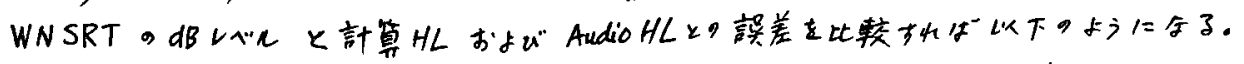

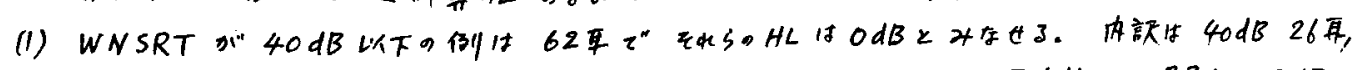

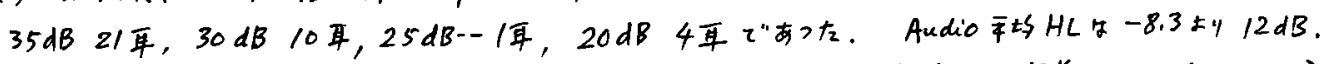

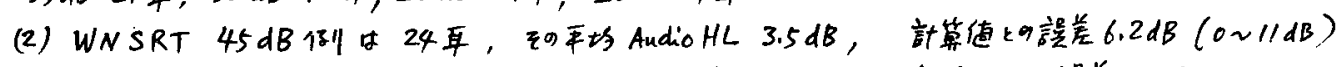

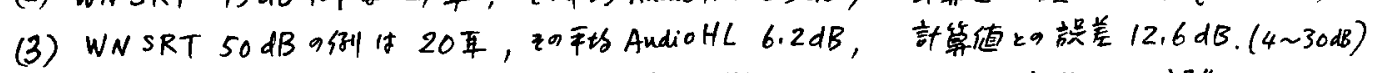

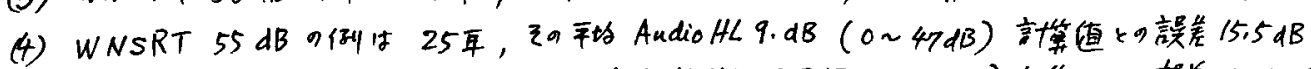

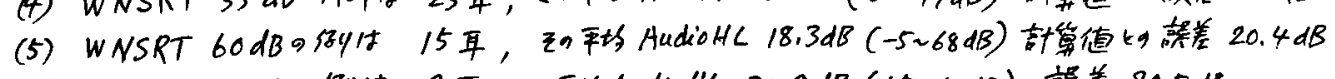

(6) WNSRT 65 dB a例は 9耷, 活平厸 AudioHL 30.9 dB (15 63dB) 鿁差 20.5 AB.

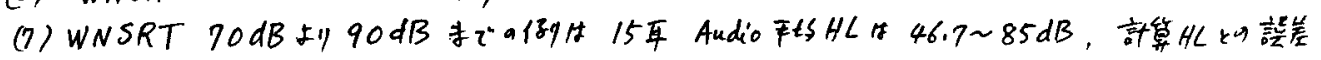

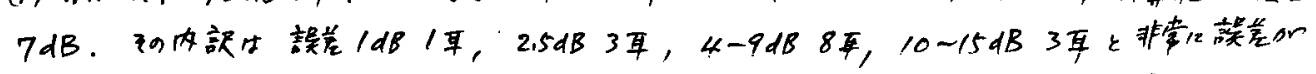

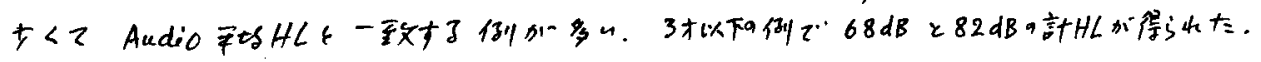
结論

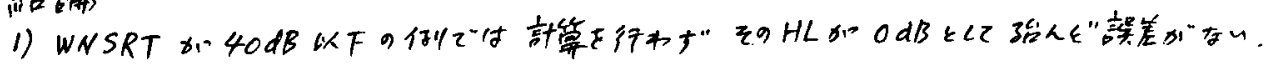

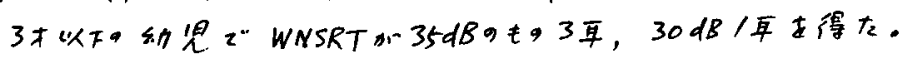

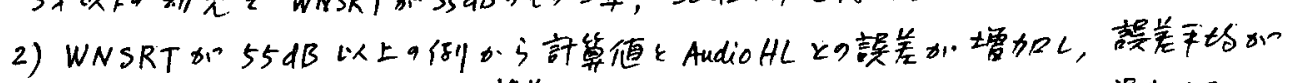

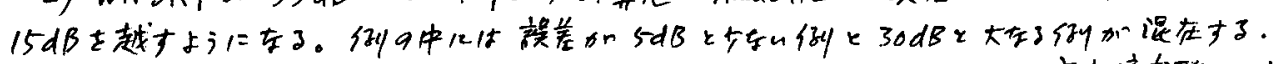

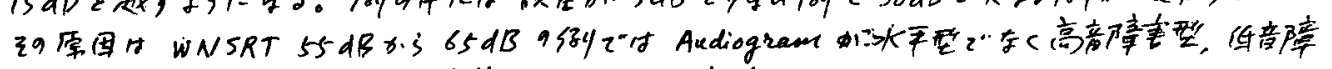

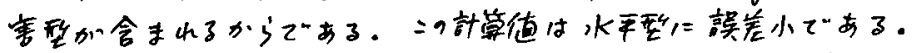

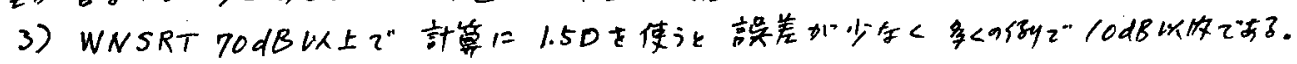
文献 Niemeyer w: Andiology 13,421-427, 1974, Jerger Jet al : Speech H. Disoider 39, 11-22,1974 